\title{
Implementation of cross-border balancing in Europe
}

\author{
L. Vandezande, L. Meeus, M. Saguan, J-M. Glachant, and R. Belmans
}

\begin{abstract}
Following initiatives on the day-ahead and intra-day stage, a cross-border approach towards real-time balancing constitutes a logical next step in the process towards an Internal Electricity Market (IEM) in Europe. Determining the real-time price for energy on which market parties need to be able to rely for last resort supply, well designed cross-border balancing markets are a key element in an efficiently functioning IEM. For the moment, balancing market designs significantly differ between countries and a coordinated approach for cross-border exchange of balancing services is lacking. This paper identifies possible distortions following an insufficient harmonization of national designs and derives both minimal prerequisites and long term recommendations for the implementation of cross-border balancing in Europe.
\end{abstract}

\section{INTRODUCTION}

$\mathrm{S}_{\mathrm{n}}^{\mathrm{I}}$ INCE the start of electricity sector liberalisation in the EU, the European Commission and the European Energy Regulating Institutions have pursued - and increasingly continue to pursue - the creation of the Internal Electricity Market (IEM). Determining the real-time price for energy on which market parties need to be able to rely for last resort supply, well designed cross-border balancing markets are a key element in an efficiently functioning IEM.

So far, a number of stakeholders have made various suggestions regarding the implementation of cross-border balancing trade [1]-[12] . Several practical initiatives have also been put forward in the context of the regions established through the Congestion Management (CM) Guidelines amending Regulation 1228/2003. In addition, following the approval of the $3^{\text {rd }}$ legislative package, Regulation 1228/2003 will - similar to the CM Guidelines - allow for the adoption of binding guidelines on the integration of balancing and reserve markets.

On this backdrop, this paper aims to derive practical recommendations as to the optimal design and effective implementation of cross-border balancing or real-time markets. The paper is organized as follows. Section II explains the basics of real-time balancing. Section III discusses distorting effects of insufficiently harmonized real-time market designs. IV identifies minimal

Manuscript received April 15, 2008.

L. Vandezande is with the Electrical Engineering Department, KULeuven, Belgium. (phone: +32-(0)16/321722; fax: +32-(0)16/321985; leen.vandezande@esat.kuleuven.be).

L. Meeus is with the Electrical Engineering Department, KULeuven (e-mail: leonardo.meeus@esat.kuleuven.be).

M. Saguan is with Groupe Réseaux - Jean Monnet, Paris XI (e-mail: marcelo.saguan@u-psud.fr)

J-M. Glachant is with groupe Réseaux Jean-Monnet, Paris XI (e-mail: jean-michel.glachant@wanadoo.fr)

R. Belmans is with the Electrical Engineering Department, KULeuven (e-mail: ronnie.belmans@esat.kuleuven.be) harmonization prerequisites for the implementation of cross-border balancing. Section V sets out long term recommendations aiming to optimize initial cross-border balancing implementation.

\section{BASICS OF REAL-TIME BALANCING}

Maintaining a real-time balance between power generated and power consumed is essential for safeguarding system security. Because of the non-storability of electricity, disturbances of equilibrium between generation and load cause the system frequency to deviate from its set value. For that reason, aberrations in demand, generation and transmission must be handled instantly.

Initially, unbalances are offset by the kinetic energy of the rotating generating sets and motors connected to the system. The more generators and motors are coupled to the grid, the more kinetic energy the system has and the larger the system's inertia. However, no matter how large the system's inertia is, it can only slow down frequency deviations and is not in the least able to restore the power balance in real-time. TSOs - entrusted with the task to guarantee system security accordingly procure balancing services in the balancing market from Balancing Service Providers (BSP). To limit the amount of services needed, TSOs furthermore discourage market parties to rely on the real-time delivery of balancing services. On that account, they partially transfer their balancing obligation to a number of market participants so-called Balance Responsible Parties (BRP) - by making them responsible for keeping their own portfolio in balance in a given time-frame via the so-called imbalance settlement. Procurement and settlement and the central role of TSOs in both are graphically represented in Fig. 1.

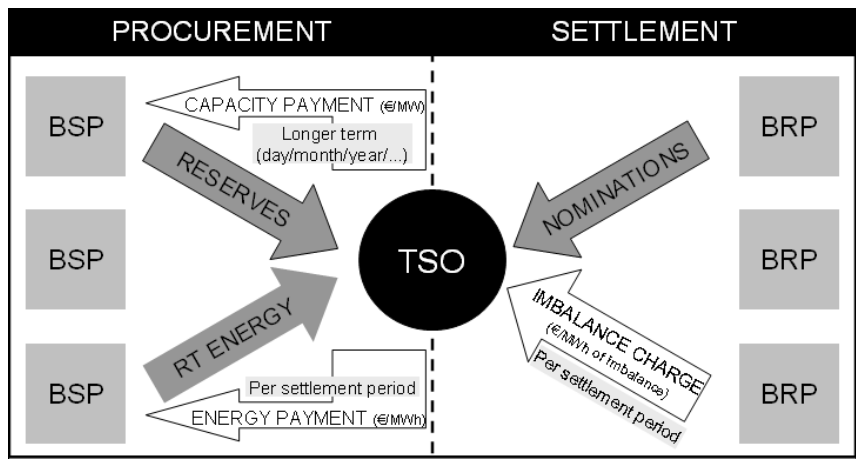

Fig. 1. Balancing services procurement and imbalance settlement

\section{A. Procurement of balancing services}

Balancing services are mainly provided by generation but - more and more - also load is contributing through contractual switching off schemes. However, technical limitations - including the lack of enabling infrastructure 
such as automatic metering and the possibility to switch off individual market parties and individual consumers' loads may still prevent maximum potential participation of the latter to the balancing market.

Typically, several types of balancing services are distinguished, which mainly differ in terms of activation method and response speed. The reason for that consists in the technical limitations of generating units, entailing a trade-off between fastness (dynamics) and sustainability of response (steady state efficiency). The terminology and technical prerequisites of balancing services largely vary between and within synchronous zones, partly because of the underlying structural differences, such as generation mix and inertia of the system [13]. For instance, the abundance of fast acting hydro plants in Nordel has led to differently defined services than those prevailing in UCTE with its rather conventional thermal generation park.

To avoid any confusion and abstract from local differences, a distinction is only made between the following comprehensive categories of services in the remainder of this document:

- Security insurance services: services mainly deployed for capacity purposes and delivering only a marginal amount of real-time energy

- Real-time energy delivery services: services mainly deployed for energy delivery purposes and delivering a substantial amount of real-time energy

TABLE I illustrates that security insurance services typically exhibit different technical characteristics than real-time energy delivery services. However, these characteristics should not be interpreted as a conditio sine qua non when determining to which category a service belongs. In order to classify currently used balancing services into one of both categories, an estimation of the yearly activated amount of the services can serve as an indication. The higher the relatively activated volumes, the more a service has been deployed for real-time energy rather than capacity purposes.

TABLE I

CATEGORIZATION OF BALANCING SERVICES

\begin{tabular}{|c|c|c|c|}
\hline & & SECURTTY INSURANGEE & REAL-TIME ENERREY \\
\hline UsE & & $\begin{array}{c}\text { Very small } \\
\mathrm{E} \text { (real-time energy delivery) }\end{array}$ & $\begin{array}{c}\text { Siguificant } \\
\mathrm{E} \text { (real-time energy delivery) }\end{array}$ \\
\hline $\begin{array}{c}\text { TEchnical } \\
\text { CHaRacteristics }\end{array}$ & (d) & $\begin{array}{l}\text { Immediate reaction } \\
\text { Provided by spinning resources } \\
\text { Delivering mainly capacity } \\
\text { Typically automatically activated }\end{array}$ & $\begin{array}{l}\text { (a) No immediate reaction } \\
\text { (b) Not necessarily provided by } \\
\text { spinning resources } \\
\text { (c) Delivering substantial amounts of } \\
\text { real-time energy } \\
\text { (d) Can also be manually activated }\end{array}$ \\
\hline
\end{tabular}

To ensure a continuous and sufficient availability of all services, TSOs often make reservations beforehand by not merely paying for the delivery of balancing services (energy or utilization payments - on a settlement period basis) via the real-time market, but also for holding reserves (capacity or availability payments - on a longer term basis) via the reserve market. As illustrated in [14]-[15], the remuneration for similar services significantly differs between countries. In addition, the time period for capacity reservations varies from an hourly to a more than one year basis.

\section{B. Imbalance settlement}

TSOs partially pass on their balancing responsibility to market participants by designation of BRPs, which are in charge for keeping their own portfolio in balance in a given time-frame via the so-called imbalance settlement, as illustrated in Fig. 2. The imbalance or real-time energy price incentivises these BRPs to match their injections and off-takes using their assets and the wholesale markets. Remaining short or long positions in real-time can only be handled by the TSO as single buyer of balancing services.

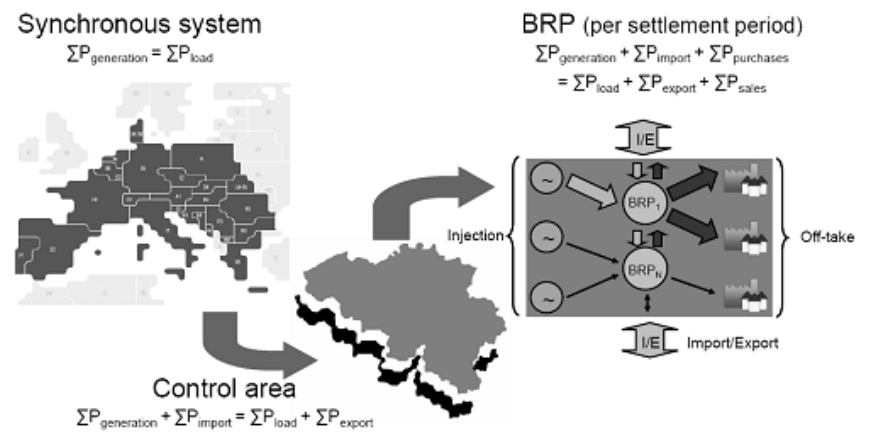

Fig. 2. TSO versus BRP balancing responsibility in UCTE

More specifically, a portfolio can consist of generation, energy purchases and imports on the one hand (injections), and industrial and residential customers, energy sales and exports on the other (off-takes). Generally speaking, a portfolio is balanced if the following equation - expressed in MW - holds over the settlement period as defined by the TSO of the control area concerned:

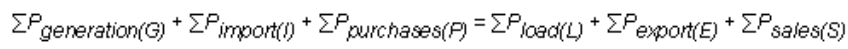

At gate closure - the time at which wholesale trade between market participants ceases - each BRP is required to declare its scheduled imports, exports and energy exchanges between BRPs and power exchanges, known as 'nominations'. These nominations have to be balanced in all European countries, except for Great-Britain. Remaining short or long positions in real-time are denoted as the BRP's imbalances.

On the basis of the BRP's imbalances incurred, an imbalance charge ( $€ / \mathrm{MWh}$ ) is imposed per settlement period on the BRPs concerned. Consequently, BRPs can weigh up whether to maximally hedge against imbalances by purchasing energy in the wholesale market or to pay for imbalances in real-time. However, given the higher volatility and unpredictability of real-time prices, BRPs exhibit a natural tendency to contract beforehand via wholesale markets rather than relying on the real-time market.

\section{DISTORTIONS FOLLOWING INSUFFICIENT HARMONISATION}

At the moment, real-time market designs significantly differ between European countries. Cross-border balancing trade without harmonization of these national designs may involve several distorting effects. However, certain design differences are already causing distortions today because wholesale trade is increasingly integrated. 
Fig. 3 illustrates potential distortions following an insufficient harmonization of imbalance pricing methods between different countries. Assume country A settles imbalances through a price system with penalties. Penalties are added to the imbalance or real-time price in many countries and this for several reasons, including the incitation of BRPs to avoid negative imbalances (Cf. infra). Penalties are typically larger for short positions than for long ones. Country B on the contrary relies on a price system without penalties. Because of the penalties, BRPs in country A will be inclined to hedge against short positions by purchasing on forward markets - which has an increasing effect on the associated market prices - and/or by keeping services for own use - which has a reductive effect on the supply of balancing services (1). In case forward markets of country A and B are integrated, the impact on forward market prices is spread over both (2). The latter indicates that distortions already exist to a certain extent today. Consequently, the more day-ahead and intra-day markets are cross-border integrated, the more a harmonization of balancing market designs becomes important. Following cross-border balancing implementation, distortions might further aggravate as a so-called "fuite de reserves" from country B to country A or, in other words, a migration of imbalances from country A to country B, may take place (3) [16].

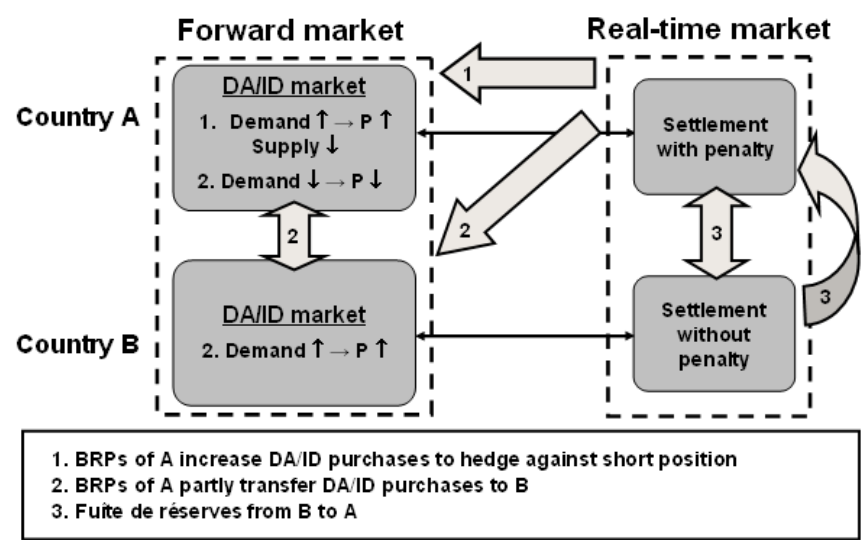

Fig. 3. Possible distortions following a non-harmonized imbalance settlement

\section{PREREQUISITES FOR CROSS-BORDER BALANCING IMPLEMENTATION}

As distorting effects related to insufficient harmonization of real-time market designs also occur without cross-border balancing trade taking place, it is recommended to proceed with cross-border balancing implementation taking into account only minimal prerequisites - to ensure a fast, but functioning implementation - and further harmonize in a later stage. A similar approach has been proven successful for the Nordic cross-border balancing initiative and the Trilateral Day-Ahead Market Coupling between Belgium, France and the Netherlands. Both initiatives have proven to trigger harmonization rather than requiring them from the start.

In order to identify harmonization prerequisites, the Nordic cross-border balancing initiative serves as a valuable reference. With its initial implementation in 2002, harmonization of real-time market designs was kept to a minimum and mainly concerned technical characteristics of balancing services, including activation time and time to full activation. During the first years of cross-border balancing trade, a call for more harmonization has gradually arisen. As a result, further harmonization steps will be implemented begin 2009. These harmonization steps mainly concern the imbalance settlement, gate closure times and the time interval for the submission of real-time energy bids in the real-time market [8]-[11].

Following the Nordic experience, prerequisites can be limited to a harmonization of technical characteristics of balancing services. However - despite Nordic practice - a harmonization of gate closure times from the start is advisable as well, given that different gate closures will lead to asymmetric market opportunities and different imbalance exposures at both sides of the border.

\section{RECOMMENDATIONS IN THE LONG RUN}

While the minimal prerequisites defined in Section IV ensure a fast and functioning implementation of cross-border balancing trade, they do not eliminate the distorting effects following a lack of harmonization as discussed in Section III. Therefore, the initial cross-border balancing implementation should be further optimized in the long run.

\section{A. Overview: need for market-based real-time energy} prices

Real-time markets provide market parties with a last resort of energy transactions. The expected prices to be brought forth by this market are reflected in wholesale prices and consequently affect market parties' decisions at the forward stage. On that account, electricity markets can only function efficiently conditionally to market-based or cost-reflective real-time energy prices. Taking market-based real-time energy prices as the point of departure, the recommendations summarized in TABLE II are derived and elaborated on below.

\section{B. Meaning of market-based}

Real-time energy prices are market-based insofar as they fully reflect all procurement expenses incurred by the TSO for real-time balancing. As such, real-time energy prices should in principle correctly pass on both energy and capacity payments.

\section{1) Allocation of energy payments}

Real-time energy or imbalance prices are usually based on the up- and downward regulating power offers accepted by the TSO for real-time balancing. Either they start from the price of the marginally accepted up- or downward regulating offer or from the average price of all accepted up- or downward regulating offers, depending on how BSPs are remunerated.

Apart from the choice between marginal and average pricing, a difference also exists between single and double imbalance pricing schemes. A typical one and two price system is schematically represented in TABLE III and TABLE IV respectively. 
TABLE II

LONG RUN RECOMMENDATIONS ON HARMONIZING REAL-TIME MARKET DESIGN

\begin{tabular}{|c|c|}
\hline \multicolumn{2}{|c|}{ Real-time energy prices should be market-based } \\
\hline Market-based means that: & Market-based implies that: \\
\hline $\begin{array}{l}\text { Imbalances in real-time are } \\
\text { settled at a price that fully } \\
\text { reflects the costs of real-time } \\
\text { balancing. } \\
\rightarrow \text { Even though there is a } \\
\text { rationale to socialize part of } \\
\text { reserves' costs, total } \\
\text { procurement costs of } \\
\text { reserves that deliver a } \\
\text { significant amount of energy } \\
\text { in the real-time should be } \\
\text { fully reflected in the } \\
\text { imbalance settlement. } \\
\rightarrow \text { An imbalance settlement } \\
\text { based on other components } \\
\text { such as power exchange } \\
\text { prices and penalties is not } \\
\text { market-based, but an additive } \\
\text { component is necessary to } \\
\text { settle capacity payments of } \\
\text { reserves procurement. }\end{array}$ & $\begin{array}{l}\text { A cap should be imposed on } \\
\text { the amount of reserves such } \\
\text { that: } \\
\text { - Their share in the energy } \\
\text { delivered in real-time is } \\
\text { marginal. } \\
\text { - The real-time energy } \\
\text { price is mainly based on } \\
\text { balancing services } \\
\text { procured. } \\
\text { As market-based solutions } \\
\text { are not always feasible on a } \\
\text { national scale, cross-border } \\
\text { balancing implementation } \\
\text { should precede market } \\
\text { design harmonization. }\end{array}$ \\
\hline
\end{tabular}

Under a single imbalance pricing scheme or so-called one price system, real-time energy or imbalance prices correspond to the marginal procurement price of balancing services, being either upward or downward regulating services depending on the overall status of the system. The same imbalance price - be it with a different sign - is applied for remaining short and long positions, making the imbalance settlement a zero sum game for the TSO. TABLE III

IMBALANCE SETTLEMENT THROUGH A TYPICAL ONE PRICE SYSTEM

\begin{tabular}{|c|c|c|c|}
\hline & & \multicolumn{2}{|c|}{ SYSTEM IMBALANCE } \\
\hline & & $\begin{array}{l}\text { NEGATIVE (short) } \\
\text { - } \quad \text { Injections \& Eotf-takes } \\
\text { - } \quad \text { TSO asks more production } \\
\text { - } \quad \text { NRV }>0\end{array}$ & $\begin{array}{l}\text { POSITIVE (long) } \\
\text { - } \quad \text { Enjections > Eoff-takes } \\
\text { - } \quad \text { TSO asks less production } \\
\text { - } \quad \text { NRV }<0\end{array}$ \\
\hline \multirow{2}{*}{ 岁 } & $\begin{array}{l}\text { NEGATIVE (short) } \\
\text { Injections < off-takes }\end{array}$ & $+\mathrm{MP}_{\mathrm{u}}$ & $+M P_{d}$ \\
\hline & $\begin{array}{l}\text { POSITIVE (long) } \\
\text { Injections > off-takes }\end{array}$ & $-\mathrm{MP}_{\mathrm{u}}$ & $-M P_{d}$ \\
\hline
\end{tabular}

$\mathrm{MP}_{\mathrm{u}}=$ marginal price of upward regulation; $\mathrm{MP}_{\mathrm{d}}=$ marginal price of downward regulation; $\mathrm{NRV}=$ net regulation volume

Under a double imbalance pricing scheme or so-called two price system on the contrary, a different imbalance price is applied for positive and negative BRP imbalances. While imbalances of BRPs contributing to the system imbalance are settled at prices based on the - usually average - procurement costs of balancing services, imbalances of BRPs counteracting the system imbalance are settled on the basis of wholesale price indices, typically power exchange prices. Compared to a one price system, which settles BRP imbalances opposing the system imbalance departing from marginal costs - i.e. the additional cost the TSO would have incurred if the BRP concerned was not imbalanced -, the latter is considered not cost-reflective. In addition, a two price system does no longer imply a zero sum game for the TSO. Accordingly, insofar the difference is not used by the TSO to cover other costs in the real-time, it should result in a reduction of transmission tariffs. But even if this is done, it still entails a transfer of money from inflexible users to average users. Furthermore, a two price system puts small market parties at a disadvantage as it involves lower imbalance costs for larger market parties due to netting. For that reason, small market parties are "gently forced" to outsource their balance responsibility. Finally, a two price system often includes a multiplicative component or so-called penalty that affects BRPs with regard to their position before real-time. Typically this penalty is affecting negative imbalances more strongly than positive ones, inciting BRPs as such to avoid short positions. Other than for BRP incitation - and related to this security safeguarding - penalties are imposed for practical reasons such as accounting - for instance to generate extra revenues for the recovery of intra-settlement period imbalances - and the recovery of capacity payments (Cf. infra). Insofar they are not cost-reflective, penalties can give rise to undesirable BRP behaviour, including over-contracting in the wholesale market, withholding services for its own use and nominating less than the expected injections.

TABLE IV

IMBALANCE SETTLEMENT THROUGH A TYPICAL TWO PRICE SYSTEM

\begin{tabular}{|c|c|c|c|}
\hline & & \multicolumn{2}{|c|}{ SYSTEM IMBALANCE } \\
\hline & & $\begin{array}{l}\text { NEGATIVE (short) } \\
\text { - } \quad \text { Enjections \& Eoff-takes } \\
\text { - } \quad \text { TSO asks more production } \\
\text { - } \quad \text { NRV }>0\end{array}$ & $\begin{array}{l}\text { POSITIVE (long) } \\
\text { - } \quad \text { Enjections }>\text { Eotf-takes } \\
\text { - } \quad \text { TSO asks less production } \\
\text { - } \quad \text { NRV }<0\end{array}$ \\
\hline \multirow{2}{*}{$\frac{\substack{u \\
\frac{Z}{4}}}{\frac{1}{\alpha}}$} & $\begin{array}{l}\text { NEGATIVE (short) } \\
\text { Injections }<\text { off-takes }\end{array}$ & $+\mathrm{AP}_{\mathrm{u}}{ }^{*}\left(1+\right.$ penalty $\left.{ }_{\mathrm{u}}\right)$ & $+P_{D A}$ \\
\hline & $\begin{array}{l}\text { POSITIVE (long) } \\
\text { Injections > off-takes }\end{array}$ & - $P_{D A}$ & $-\mathrm{AP}_{d} /(1+$ penalty $)$ \\
\hline
\end{tabular}

$\mathrm{AP}_{\mathrm{u}}=$ average price of upward regulation; $\mathrm{AP}_{\mathrm{d}}=$ average price of downward regulation; $\mathrm{NRV}$ = net regulation volume; $\mathrm{P}_{\mathrm{DA}}=$ day-ahead power exchange price

\section{2) Allocation of capacity payments}

Contrary to energy payments, capacity is procured for a time period far exceeding the settlement period. Consequently, its associated costs cannot be directly attributed to imbalanced BRPs. Therefore, a choice should be made between one of the following cost allocation methods.

(1) Socialization among grid users via transmission tariffs

A socialization of capacity payments among grid users does not entail cost-reflective real-time energy prices: it results in too low real-time energy prices as they do not include all procurement costs. Consequently, BRPs get fewer incentives to balance their portfolio using wholesale markets and increasingly rely on the real-time market. 
A socialisation of capacity payments is however justified for security insurance services, which are mainly deployed for capacity purposes and should accordingly only be remunerated for capacity. As these services mostly operate as a kind of public security insurance, their costs should not be allocated to individual BRPs. To avoid over-contracting by TSOs and consequently protect grid users against too high transmission tariffs, the amount of capacity payments for security insurance services should be regulated.

Current practices of capacity cost socialisation among grid users are manifold. Typically countries reasonably pass through the costs of primary reserves on grid users. Many countries do however allocate the costs of other services deployed for real-time energy delivery rather than capacity purposes - via the transmission tariffs as well.

(2) Socialization among BRPs via periodical fee

Although a socialization of capacity payments among BRPs is already an improvement on the previous method, it does not yet provide BRPs with correct incentives. Since the periodical fee is fixed ( $€$ /period) or proportional to BRPs' injections or off-takes ( $€ / M W h$ of injections/off-takes) - i.e. BRPs' size - rather than proportional to BRP's imbalances, real-time energy prices will again be too low, incentivising BRPs to over-rely on the real-time energy market.

Note that countries having implemented a pure one price system can only pass through energy costs via the real-time energy price and do have no other choice than allocating capacity costs via socialization among grid users or BRPs. Consequently, pure one price systems - like two price systems with non-market based components - are not market-based.

Current practices of socialization among BRPs include:

- In France, a monthly fee - the so-called "prix proportionnel au soutirage physique" - is imposed on BRPs proportional to their off-takes to recover capacity payments of the "réserves rapides" (15' reserves).

- In Great-Britain, capacity payments are partly allocated to BRPs via the so-called "BSUoS charges", a fee imposed per settlement period $(1 / 2 \mathrm{H})$ proportional to BRPs' injections or off-takes.

- In the Nordic countries, a harmonized imbalance settlement will be implemented begin 2009 that partly allocates capacity costs through a monthly fixed fee and a fee proportional to BRPs' measured generation or consumption.

(3) Allocation to imbalanced BRPs via additive component

The third and most market-based method consists in an inclusion of capacity costs in the real-time energy price ( $€$ /MWh of imbalances). Such an allocation of capacity payments is similar to the allocation of fixed costs under so-called Ramsey-Boiteux pricing, whereby fixed costs are recouped from customers by charging them prices in excess of marginal costs and this in inverse proportion to their demand elasticities [17]. Similarly, capacity payments can be recovered by means of an additive component (component cap ) on top of the marginal procurement price of upward or downward regulating services $\left(\mathrm{MP}_{\mathrm{u} / \mathrm{d}}\right)$. Inelastic customers in this case include all BRPs that "chose" to be imbalanced despite a real-time energy price higher than the marginal cost of upward or downward regulation. The allocation of both energy and capacity payments through the real-time energy price is summarized in TABLE $\mathrm{V}$.

TABLE V

ALLOCATION OF CAPACITY PAYMENTS VIA THE REAL-TIME ENERGY PRICE

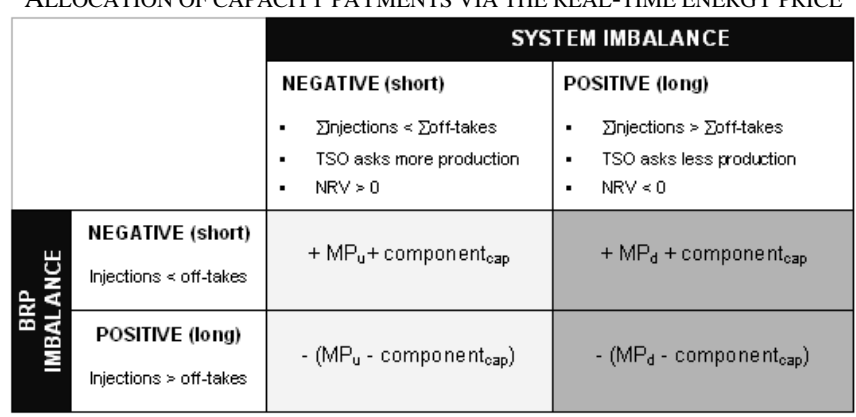

$\mathrm{MP}_{\mathrm{u}}=$ marginal price of upward regulation; $\mathrm{MP}_{\mathrm{d}}=$ marginal price of

downward regulation; $\mathrm{NRV}=$ net regulated volume; component $_{\text {cap }}=$ additive component

Note that the resulting imbalance pricing system exhibits characteristics of a one as well as two price system. Similar to a one price system, it allocates energy costs using marginal procurement prices only. Similar to a two price system, it entails different real-time energy prices depending on the sign of the BRP's imbalance, but - contrary to a two price system - without including non-market based components.

To ensure a cost-reflective real-time energy price, an accurate determination of the additive component is primordial. Spreading out capacity payments over all imbalanced BRPs during the time period of capacity reservation, the additive component can only be calculated using historical figures regarding the amount and magnitude of BRP imbalances. Consequently, an exact recovery of capacity payments via the additive component is out of reach. Moreover, the longer the terms of capacity reservation, the less accurate the additive component will be. Therefore, from a cost allocation point of view, capacities are preferably procured on a short term basis. However, the impact of shorter reservation periods on competition is uncertain. On the one hand, short term capacity payments reduce market foreclosure, on the other hand they might provide incumbents with the opportunity to game on a more regular basis. On that account, the optimal length of the reservation period should be defined taking into account the impact on both cost allocation and competition.

Current practices of an additive component in the real-time energy price include:

- In the Nordic countries, the harmonised imbalance settlement proposal to be implemented begin 2009 foresees a volume fee on consumption imbalances to recover part of the capacity payments.

- In Austria, the imbalance settlement system applied since 2006 allocates capacity costs through a component included in the real-time energy price that progressively increases proportional to the magnitude of the system imbalance during the settlement period concerned.

Note that in both cases, the additive component has been implemented in such way that it provides additional - but 
redundant or even wrong - incentives to BRPs, which should of course be avoided:

- In the Nordic countries, the additive component is only imposed on negative imbalances, which incentivises BRPs - similar to a penalty under a two price system - to be long rather than balanced.

- In Austria, the progressively increase of the additive component is achieved through addition of a non-market based component acting as a kind of "security penalty".

\section{Implications of market-based}

The implementation of a market-based real-time design as discussed above has two major implications.

1) Need for restrictions on the amount of reserves

The allocation of capacity payments via an additive component has a negative impact on new entrants - being the most inelastic customers since they usually do not have the possibility to balance their own portfolio - rather than incumbents. Therefore, the reservation of balancing services mainly deployed for real-time energy delivery should be kept to a minimum. Consequently, in order to avoid barriers to entry, a cap should be imposed on the amount of reserves such that the share of component ${ }_{\text {cap }}$ in the final real-time energy price is small compared to the marginal upward or downward regulation price. As a rule of thumb, reservations of real-time energy delivery services should only be accepted insofar as needed to compensate for the higher revenue volatility in real-time markets compared to wholesale markets and to deal with non-convexities [18]. The appropriateness of the level of the imposed cap can be verified through monitoring whether (1) the real-time energy delivery of the reserves concerned is marginal and (2) the additive component only marginally affects the real-time energy price.

The actual relevance and necessity for a regulated amount of reserves is only reinforced by the fact that several TSOs' currently consider substantially increasing the amount of reserves or even building their own plants - being an extreme form of capacity payments - to ensure sufficient availability of services for real-time energy delivery purposes. A lacking confidence in the real-time market and an associated fear for a shortfall of reserves are often at the basis of these intentions. However, over-contracting of reserves entails several negative side-effects:

- It reduces trade opportunities in the wholesale market and accordingly increases price differences between the wholesale and real-time market.

- It has a reductive effect on real-time energy prices - even in case of scarcity - which could finally result in a disappearance of the real-time market.

- It might increase moral hazard by granting BRPs the implicit guarantee that all imbalances can be covered by reserves procured by the TSO.

2) Infeasibility of a market-based design on a national level

Currently implemented real-time market designs across Europe often significantly deviate from the above proposed recommendations. However, these deviations are understandable in a national context, considering market concentration and the (non)-existence of a well-functioning intra-day market [19]. As such, concentration simply does not allow some real-time markets to function properly on a national scale. This explains why many real-time "markets" are currently more regulated than market based. The potential infeasibility of a market-based design on a national scale reinforces the recommendation formulated in Section IV to implement cross-border balancing first and only harmonize real-time markets at a later stage.

\section{REFERENCES}

[1] European Commission (DG TREN). Benefits and Practical Steps towards the Integration of Intraday Electricity Markets and Balancing Mechanisms, December 2005, Available at http://ec.europa.eu/energy/index_en.html

[2] European Energy Regulators (ERGEG \& CEER). Guidelines of Good Practice for Electricity Balancing Markets Integration, December 2006, Available at http://www.ergeg.org

[3] ETSO. Current state of trading tertiary reserves across borders in Europe, November 2005, Available at http://www.etso-net.org

[4] ETSO. Key Issues in Facilitating Cross-border Trading of Tertiary Reserves and Energy Balancing, May 2006, Available at http://www.etso-net.org

[5] ETSO. Balance management harmonisation and Integration. $4^{\text {th }}$ Report, January 2007, Available at http://www.etso-net.org

[6] Eurelectric. Towards European intra-day and balancing markets, October 2006, Available at http://www.eurelectric.org

[7] Eurelectric. Towards integration of reserves and balancing markets. July 2008, Available at http://www.eurelectric.org

[8] Nordel. Balance Management - Common principles for cost allocation and settlement, April 2006, Available at http://www.nordel.org

[9] Nordel. Harmonization of the balance management, February 2007, Available at http://www.nordel.org

[10] Nordel. Proposed principles for common balance management, November 2007, Available at http://www.nordel.org

[11] Nordel. Description of balance regulation in the Nordic countries, March 2008, Available at http://www.nordel.org

[12] UCTE. Ad hoc group 'Geographical Distribution of Reserves', July 2005, Available at http://www.ucte.org

[13] Rebours Y., Kirschen D., Trotignon M. and Rossignol S. A Survey of Frequency and Voltage Control Ancillary Services - Part I: Technical features, IEEE Transactions on power systems, 2007, 22 (1), 350-357

[14] Rebours Y., Kirschen D., Trotignon M. And Rossignol S. A Survey of Frequency and Voltage Control Ancillary Services - Part II: Economic Features, IEEE Transactions on power systems, 2007, 22(1), 358-366

[15] Vandezande L., Meeus L. and Belmans R. The next step in the central Western European market: cross-border balancing, Revue e tijdschrift, 124(1), March 2008

[16] Saguan M. L'Analyse economique des architectures de marché electrique. Application au market design du «temps réel », Thèse pour le Doctorat en Sciences Economiques, Université Paris-Sud 11, Faculté Jean-Monnet, April 2007 and Saguan M. and Glachant J-M. (2007). An Institutional Frame to compare Alternative Market Designs in EU Electricity Balancing, Working Paper MIT-CEEPR, January 2007

[17] The argument of Ramsey-Boiteux pricing has been used similarly by Hogan with respect to the allocation of so-called "Resource Sufficiency Costs” in Midwest USA (MISO): Hogan W. W. Revenue efficiency and cost allocation. Comments submitted to the Federal Energy regulatory Commission, May 25, 2006, Available at http://ksghome.harvard.edu/ WHogan/Hogan_RSG_052506.pdf

[18] For a simple explanation on non-convexities in electricity markets, see for instance Meeus L. Power exchange auction trading platform design, PhD, K.U.Leuven, ESAT-ELECTA, July 4, 2006,152 pages.

[19] Littlechild S. Electricity cash-out arrangements, 9 March 2007, available at http://www.cornwallenergy.com 